\title{
A representação em Carl Schmitt: 0 catolicismo romano e 0 caso da política
}

\author{
The representation in Carl Schmitt: Roman Catholicism and the \\ purpose of politics
}

\section{Roberto Bueno*}

Universidade de Brasília, Brasília, DF, Brasil

\section{Resumo}

Este artigo analisa a grave crise do conceito de representação política a partir do Catolicismo Romano e forma Política de Carl Schmitt. O artigo propõe alargar as vias de compreensão da crise de representação política das democracias liberais de mercado, realizando aproximação ao tema através de duplo movimento expansivo, tanto dos campos de força cognitivos acerca da representação política e de seu enraizamento econômico, nas políticas promotoras da turbação da legitimidade da representação política.

Palavras-chave: Carl Schmitt. Representação. Teologia. Catolicismo.

* RB: Doutor, e-mail: rbueno_@hotmail.com 


\section{Abstract}

This article analyzes the serious crisis of the concept of political representation from the Roman Catholicism and Political Form of Carl Schmitt. The article proposes to widen the ways of understanding the crisis of political representation of liberal market democracies by approaching the issue through a double expansive movement of both the cognitive fields of force on political representation and its economic rootedness in the policies promoting the disruption of the legitimacy of Political representation.

Keywords: Carl Schmitt. Representation. Theology. Catholicism.

\section{Introdução}

A representação política é chave nas discussões da filosofia política e desfruta de considerável atualidade nas democracias modernas, em face do recrudescimento e aprofundamento dos vetores da crise política, tanto do ponto de vista conceitual quanto em sua intersecção empírica. Eixo de sustentação do conceito de legitimação, a representação é um dos temas centrais da crise das democracias contemporâneas, posto que projeta a realização da vontade política popular nas esferas da construção do ordenamento legal, através das ações de instâncias mediadoras como o Poder Legislativo e o Poder Executivo e, sobretudo, entre o Estado e as instâncias da sociedade.

As intransitividades, rupturas e descontinuidades entre as duas esferas volitivas de construção política e a esfera pública caracterizam um dos mais difíceis dilemas das democracias contemporâneas, mas não menos intensamente, a própria via de atualização da positivação da vontade política, em sua tradução ao mundo jurídico, que requer uma mediação-decisão humana e que em Schmitt, se resolve na figura do soberano que enfeixa todo o poder e o expressa como se fosse a própria concretização da vontade geral rousseauniana. Mas, é no fato da desconsideração desta mediação conjugada com a identificação da concentração muito particular de interesses a ser evitada que deparamos 
com ataque visceral a democracia parlamentar com a oferta de opções autoritárias às suas crises e graves dilemas.

Em sua gênese, o conceito de representação não se mostra historicamente vinculado à escolha popular para a constituição de um determinado sistema político. A indefinição sobre a preeminência ou não do povo e de seus interesses em uma determinada ordem é, indubitavelmente, um tema nevrálgico do pensamento político (cf. SÁ, 2015, p. 131). Isto ocorre especialmente em Schmitt (cf. KELLY, 2004, p. 114), muito embora sua crítica à democracia parlamentar possa ser classificada como oscilante entre uma elaboração autoritária (cf. SÁ, 2015, p. 130) - acaso isto já não derive de seu próprio modelo de Igreja $^{1}$ (cf. Mc CORMICK, 1997, p. 160) - e uma fascista (cf. BARNETT, 2004), mas que continuadamente manteve posição crítica à democracia parlamentar (cf. SÁ, 2015, p. 130).

A introdução de uma perspectiva democrático-participativa e constitutiva da representação laica orientada pelo interesse popular reputado soberano pelas vias do liberalismo político clássico é expressiva da concepção de mundo moderna pautada pelo racionalismo liberal. A autossuficiência racionalista compõe sistema aspirante a completude mas que é, à diferença da prerrogativa divina, insuficiente para fundar tão densamente a imanência quanto este modelo transcendente é capaz e, assim, que a fundamentação política do Estado e de sua autoridade em sua subjetividade "[...] no puede prescindir de la creencia en el fundamento trascendente de la autoridad" (PÁEZ CANOSA, 2016, p. 615). O radical distanciamento liberal das vias teológico-políticas é comprometedor das chances de êxito de qualquer projeto libertário, razão pela qual a mediação política socialista ou liberal não poderia ser exitosa, crítica compartilhada por Schmitt com Donoso Cortés ${ }^{2}$.

A democracia parlamentar de corte liberal manteve a pretensão de cortar os vínculos teológicos da política, movimento que aproxima

10 próprio modelo da Igreja Católica que Schmitt pretende transmigrar para o Estado possui uma influência decisiva de uma cultura antiparlamentar e antiliberal consagrada na Encíclica Syllabus, aliás, sempre alvo de fartos elogios por parte do catolicismo autoritário de Donoso Cortés de cujos textos Schmitt foi atento leitor.

2 Para uma melhor leitura da conexão desta crítica com a filosofia política hobbesiana, sua teoria da representação e a ligação desta com o catolicismo, ver Dotti (DOTTI, 2014, p. 33). 
à compreensão sobre o sentido da oposição visceral de Schmitt a democracia liberal. Ínsito a este movimento subsiste dura oposição ao fortalecimento da autonomia individual em face de uma cosmovisão política como a schmittiana, orientada pela submissão proveniente do modelo hierárquico da estrutura da Igreja Católica ${ }^{3}$, mas também da capacidade de obter obediência, que deriva justamente do conceito de representação e quais são as suas razões (cf. PÁEZ CANOSA, 2016, p. 611). Schmitt manteve a sua fé nele e reconhecimento de sua virtude quanto à recomendação da submissão a um Deus onipotente, frente a quem necessariamente se deveria emudecer (cf. SCHMITT, 2016, p. 335). Mas se esta era uma posição compartilhada com Donoso Cortés, certamente a tradição ilustrada causaria sério impacto em ambos, e a este respeito Marder chama a atenção para a importância da percepção schmittiana sobre as graves consequências do eclipsamento de Deus no mundo pela via da metafísica no século XVIII, quando Deus passa de essência a mero conceito (cf. MARDER, 2008, p. 30).

A análise do conceito de representação política em Schmitt parte de seu Catolicismo Romano e forma Política, excedendo os limites de uma abordagem historiográfica e cuidando dos dilemas que se projetam sobre o Estado, a democracia e a vida parlamentar. A análise propõe o alargamento das vias cognitivas de acesso ao miolo da crise de representação política das democracias ocidentais contemporâneas, cujo enraizamento marcadamente liberal e mercadológico-economicista recebe crítica atual já no texto schmittiano de 1923.

A representação pode ser observada na doutrina medieval sob a pretensão de ligar o poder nominal à prática do poder político por meio do conceito de delegação de seu exercício por parte de seu titular. É possível caracterizar o conceito de representação na Idade Média pela inocorrência de uma transferência real de poder “[...] porque según esta el representante no tenía por qué ser un representante elegido, por

\footnotetext{
30 tratamento do conceito de submissão não põe em causa a crítica à defesa da ordem e nem 0 estabelecimento das condições de cumprimento dos mandatos legais tal como aparece, por exemplo, em Hobbes. No estado de natureza é fugidia ao homem a segurança, mas a submissão à ordem implica em construção coletiva de fazer político tendente a esta tal garantia, vale dizer, à emanação do poder de baixo para cima, e não de cima para baixo, conforme se ocupa de afirmar a tradição política de Donoso Cortés e Carl Schmitt.
} 
lo que podía legitimar al absolutismo monárquico" (POLACK, 2011, p. 57). Este movimento de desvinculação entre a encarnação do poder por delegação, ou eleição para outra configuração da autoridade logo se mostraria de utilidade para os propósitos das teorias autoritárias.

A aparição da forma de representação no âmbito estatal e em suas instituições ocorreu entre os séculos XVI e XVII de forma concomitante com a emersão do poder soberano e absoluto (cf. CASTIGLIONE, WARREN, 2006, p. 3), apresentado segundo um modelo monárquico capaz de ordenar a tudo e a todos, tal qual o Deus cartesiano. Por outro lado, o aparecimento das modernas instituições parlamentares nos séculos XVIII e XIX foi caracterizado por uma passagem lenta e gradual de um modelo de representação personalista para outro, cujo perfil já era marcado por instituições difusas (cf. $I b$.), ou seja, da transcendência para a imanência (cf. PÁEZ CANOSA, 2016, p. 614), de um modelo de originária dominação por aquisição (regnum patrimoniale) para outro modelo em que a origem está a instituição (regnum institutivum) por uma coletividade.

Neste momento de imersão na modernidade o soberano deixa de habitar a parte superior da hierarquia do poder e passa a ocupar a posição inferior da estrutura piramidal da política, e isto denota a perfeita inversão da perspectiva schmittiana de que a Salvação reside no ápice da pirâmide ocupada por Deus, mas não em que o próprio homem se converta na divindade, muito embora em sua concepção da política alguém possa ocupar a posição de força e poder que Ele dispõe (ver SCHMITT, 1996, p. 4). É pelo distanciamento desta perspectiva patrocinada pela modernidade que Schmitt detecta uma grave crise de representação, verdadeira impotência estrutural para realizar a genuína representação em face da inspiração moderna através de seu pensar tecnicizante e econômico.

Esta estratégia moderna é compatível com a maximização de roteiros filosóficos de corte racionalista, capazes de parametrizar a vida humana através da projeção da relação de cálculo e benefício, fossem eles pautados por regimes políticos socialistas ou liberais. O racionalismo foi legado como instrumento operativo da lógica do Estado, mas também como argumento para a crítica às possíveis derivações 
antisseculares. De qualquer sorte, toda esta é uma realidade contra a qual se põe o catolicismo, cujo doutrinário disponibiliza forte argumento contra a materialidade mundana tão bem alimentada pelo racionalismo, ou seja, como diz Schmitt, que "Denn dieser Idee widerspricht alles, was das ökonomische Denken als seine Sachlichkeit und Ehrlichkeit und seine Rationalität empfindet" 4 (SCHMITT, 2008, p. 23).

Nesta cena política o fundamento legitimador era a vontade do monarca absoluto, mas que já ia conhecendo o seu ocaso. No momento histórico seguinte se afirmaria um estágio de fundamentação popular das instâncias da autoridade política, momento moderno que se poderia denominar de passagem para a secularização da soberania ${ }^{5}$ e, por conseguinte, da autoridade. O Catolicismo Romano é esforço no sentido de criar um modelo de autoridade (cf. CAMPDERRICH BRAVO, 2011, p. XXII), mas também de exigência de obediência, para superar os dilemas de época, e para isto a estabilização do conceito de representação opera de forma central no trabalho, aliás, talvez "[...] el único capaz de servir de orientación para frenar las tendencias disgregadoras de la paz social propiciadas por el liberalismo, primero, y por el bolchevismo ruso, después" (CAMPDERRICH BRAVO, 2011, p. XXII) ${ }^{6}$. Em seu ápice este modelo está composto de um conceito de decisão que não pode ser compreendido como oposto a complexio oppositorum típica do Catolicismo Romano como sugere Galli (cf. GALLI, 2011, p. 64; ver SÁ, 1998, p. 7), e sim como necessário complemento seu na esfera da

40 trecho comporta a seguinte livre tradução: "A ideia política do catolicismo contradiz tudo o que o pensamento econômico crê ser a sua objetividade, sua integridade e sua racionalidade".

50 moderno precisa ser abordado, pois carrega em si um nada que é um problema (cf. GALLI, 2011, p. 73), e isto pode ser analisado desde a assunção de que o moderno não passa da secularização da tradição teológica cristã e jamais da criação ou evolução das categorias do espírito para novas formas históricas (cf. GALLI, 2011, p. 77) e que, portanto, a solução é abandonar o processo secularizador da modernidade que resolve a instância mediadora da política na estrutura parlamentar representativa e não em uma estrutura hierárquica de tipologia católico-romana. Schmitt apresenta a influência de Donoso Cortés de quem recepciona a noção de que a modernidade é um projeto que defenestra a virtude, posto entronizar uma teologia deficiente, ou seja, o liberalismo, que também pode ser classificada como satânica quando apresenta a sua face socialista ou anárquica (cf. D’AURIA, 2010, p. 62).

60 ataque de Schmitt ao bolchevismo é bastante afinado aquele patrocinado pelo catolicismo donosiano inspirado na Syllabus e também na filosofia conservadora revolucionária da direita alemã da primeira metade da década de 1920.

Rev. Filos., Aurora, Curitiba, v. 29, n. 47, p. 455-479, maio/ago. 2017 
imanência política, e que em Schmitt opera como uma força superlativa, ainda que algo tardia relativamente ao seu ápice medieval.

\section{Representação, identidade e as vias do catolicismo romano}

O primeiro passo ao tratar do problema da representação é abordar o significado de um conceito que em Schmitt exerce função de contenção de tendências anti-estatais (cf. PÁEZ CANOSA, 2016, p. 611) a cujo moderno corte pluralista se opõe Schmitt. A representação exerce um movimento em sentido aglutinador e unificador, quando não mesmo de concretização da homogeneização, algo possível através da encarnação da representação na figura do soberano. Historicamente, o pensamento político moderno esteve marcado pelo conceito de representação, autenticamente "[...] central para caracterizar el ámbito de la institución de lo político y la comprensión de la racionalidad política" (TRUCCO, 2012, p. 25).

Dotti, por seu turno, propõe uma importante aproximação ao conceito ao indicar necessária uma mediação realizada entre o "[...] principio sustancial del orden estatal de tipo transcendente [...] y la realidad de la convivencia en un orden estructurado por la soberanía [...] en correlación con el apotegma teológico político básico [...]" (DOTTI, 2014, p. 29), enfim, uma estrutura mediadora entre o visível e o invisível. A representação se configura como um movimento tendente à legitimação do poder imanente cujas raízes apontam primitivamente para a transcendência, logo deslocado para um modelo hierárquico forte organizado de cima para baixo (e nunca em movimento inverso) capaz de calçar o poder temporal.

Schmitt concebeu a representação de forma diversa do modelo das democracias ocidentais ${ }^{7}$ mas que com ela dialoga através de seu

7 Dotti realiza sugestiva aproximação ao conceito de representação em seu contexto teológico ressaltando que "[...] la representación político-jurídica consiste en una mediación entre el fundamento o principio sustancial del orden estatal, de tipo transcendente (distinto del criterio pragmático en el sentido del cálculo de costos-beneficios) y la realidad de la convivencia en un orden estructurado por la soberanía, por un dinamismo metaforizable espacialmente como vertical (el mando procede desde arriba hacia abajo, en correlación con el apotegma teológico político básico, vigente - en creciente enervación por la secularización - de hecho y como premisa de la legitimidad estatal: todo el poder viene de Dios) [...]". (DOTTI, 2014, p. 29). 
intuito pacificador. Para Schmitt a representação implicaria dar visibilidade ou encarnar valores ou ideais (cf. CAMPDERRICH BRAVO, 2011, p. XXIV) que não se encontram na esfera da visibilidade, ou seja, que "No se trata entonces de una relación entre particulares, sino de la producción de un orden inmanente a partir de un fundamento que no admite cuestionamientos por encontrarse en un más allá y más arriba" (PÁEZ CANOSA, 2016, p. 612). Este é o movimento que a Igreja Católica faria relativamente aos substantivos ideais de Cristo, a quem encarna e dá visibilidade no mundo através de sua atividade de mediação realizada de forma perfeita. Portanto, a sua intervenção no mundo "[...] equivale a una especie de transubstanciación de ideales en una institución y, más concretamente, en la identificación o encarnación de esos ideales en una o varias personas dirigentes insertas en esa institución" (CAMPDERRICH BRAVO, 2011, p. XXIV). Esta relação entre a transcendência (teologia católica) e a imanência (política) é também expressa por Schmitt ao sustentar que os mecanismos da política são extensíveis ao catolicismo, pois como já observou Marder em sua leitura do conceito de complexio oppositorum, é justamente "[...] one of such concepts and a more general link in the transition from the theological to the political [...] that combines a singular religious doctrine with the universality of political form" (MARDER, 2008, p. 31). Está presente nisto um raciocínio não precisamente afinado com a máxima schmittiana acerca da origem teológica de todos os conceitos significativos na moderna teoria do Estado, e isto dialoga com Schmitt ao afirmar que "A mecânica política tem as suas próprias leis, que são extensivas ao catolicismo como também a qualquer outra grandeza histórica implicada na política" (SCHMITT, 2009, p. 27).

Sugere Campderrich Bravo que a representação em Schmitt pode ser compreendida como a realização ou atualização de "[...] un ente transcendente, extramundano, Dios, es decir, lo transforman en una realidad actuante en el mundo de los hombres y lo convierten en un principio generador de orden mundano" (CAMPDERRICH BRAVO, 2011, p. LXXVIII). A aplicação da representação para a esfera temporal implica a concretização por parte de homens de princípios enunciados pela Constituição 
enquanto documento materializador das aspirações públicas compartilhadas. Neste sentido aponta Dotti que encontramos a intersecção entre o transcendente e o temporal na "[...] mediación teológico-política es [que] esta sustancialidad configurativa (una suerte de eîdos moderno) que penetra en la realidad en virtud de la decisión del sujeto politico [...]" (DOTTI, 2014, p. 31), e é esta que virá a determinar os elementos que "[...] dan realidad o efectivizan aquellos principios". (DOTTI, 2014, p. 31).

Partindo desta perspectiva conectiva entre o político (imanência) e o teológico-católico (transcendência) Schmitt elabora duas concepções sobre a representação, a saber, a Vertretung ou Stellvertretung (delegação) - no caso do Papa, o Stellvertreter Christi - e a segunda delas a Repräsentation (representação), diferenciação que logo receberia o apoio de Voegelin (cf. RIVERA, 2012, p. 88). A Vertretung diz respeito a um simples mandato ou delegação, típica da vida civil, instrumento conceitual através dos quais outorgamos poderes ou procuração a alguém para agir em nome do outorgante e, portanto, é conceito que desliza nos vãos da esfera da vida privada que tão bem se coaduna com o sistema parlamentar que apenas expressa a multiplicidade de interesses privados, ou seja, se trata de se trata de uma falsa representação. Mas para Schmitt estes interesses privados são incompatíveis com o verdadeiro sentido da representação política, posto que esta forma privatista contrapõe à expressão da unidade do povo (cf. CÓRDOVA VIANELLO, 2010, p. 255), genuíno tipo inverso da representação da ordem política que é a representação espiritual (cf. RUIZ MIGUEL, 2000, p. XXVI).

A representação típica da modernidade é aquela em que o representante tem de enfrentar o ácido problema de exercer seu mister a partir do nada, uma vez que o mundo está destituído de sentido e de substância divina, ou seja, que "La persona representativa moderna se enfrenta a una ruptura con el fundamento trascendente que lo obliga a crear el orden de la nada, a representar a un autor que no está presente" (POLACK, 2011, p. 60). Mas se esta transcendência não encontra recepção no âmago da modernidade, isto sim, outros meios de substancialização são encontrados no mundo, e um deles é o documento constitucional, cuja juridicidade se procura dotar de um caráter intangível nas democracias 
consolidadas. É nesta medida que surge o problema schmittiano ao expor que o direito não pode realizar a si mesmo, senão que está sempre a demandar uma configuração especial, particular, a cada momento que busca a sua efetivação (ver SCHMITT, 2009). Daí a necessidade da representação, condição necessária, e mesmo indispensável, para que a substância se concretize no mundo, e tal mediação é apenas possível através da figuração humana.

A representação dos altos interesses das grandes empresas transnacionais se faz operar na esfera econômica e financeira no âmbito da mera delegação de poderes, interesses que são encarnados por alguns de seus executivos, o que é explicitado ao propor que os grandes conglomerados de poder social não deixam de usar esta privilegiada posição para também conectar-se ao poder estatal (cf. SCHMITT, 2008, p. 29) ${ }^{8}$. De forma paralela, Schmitt identifica indivíduos como intelectuais e comerciantes que à época da máquina econômica moderna operam como meros servidores deste grande e pesado mecanismo (cf. SCHMITT, 2008, p. 33) $)^{9}$, serviço que tem vez e lugar quando o poder genuinamente político é dominado. Assim, perderia sentido qualquer tentativa de arranjo entre o pensamento econômico e o pensamento político, e este é precisamente o instante em que "[...] nasce um novo tipo de política a serviço do novo poder estabelecido sobre uma base econômica" (SCHMITT, 2008, p. 29), base econômica que é quem verdadeiramente termina por controlar o cenário político e deslocar o político de sua real natureza.

Na perspectiva schmittiana há uma espécie de representação que não desfrutaria da mesma dignidade que a Igreja Católica, posto o tipo de representação dos bens espirituais que encarna. Há nesta oposição entre ambas as tipologias uma inconciliável diferenciação, eis que entre as funções de representação desempenhadas por um bispo,

8 Literalmente diz Schmitt em seu texto que "Isto significa, desde uma perspectiva política consequente, que determinadas agrupações sociais de poder (poderosos empresários privados ou o conjunto organizado dos trabalhadores de determinadas empresas ou setores industriais) utilizam sua posição no processo produtivo para conseguir o poder estatal".

9 Textualmente, diz Schmitt que "Seitdem die Maschine des modernen Wirtschaftslebens läuft, sind beide immer mehr zu Bedienern der großen Maschine geworden, und es ist schwer zu sagen, was sie eigentlich repräsentieren" (SCHMITT, 2008, p. 33). 
ou aquelas realizadas por um perfil de homem de negócios ou ainda por um membro do parlamento medeia ampla distância. A rigor, no exercício de suas funções, pode acabar sendo concretizada confusão entre a representação operante na esfera pública que havia sido tornada espaço para a expressão de interesses privados e já não mais a valores substantivos (cf. McCORMICK, 1997, p. 196), esta última típica da representação exercida pela Igreja Católica, que realiza de forma substancial ou existencial.

Schmitt elabora a noção de representação política sob o conceito de Repräsentation, que pressupõe uma negação da "presença", ou seja, a ausência de um ente que será presentificado ou encarnado pela representação. O que não está, ou seja, o ente invisível, é o que precisa ser "presentificado", e é através do representante que o ausente logra esta "presentificação". No contexto da Igreja que é utilizada como modelo por Schmitt, recorda Sá que representar significa "[...] tornar visível e apresentar, através de um ente visível, exposto a presente publicamente, um ente que só adquire existência visível através do processo representativo" (SÁ, 2015, p. 134). Sem embargo, este representar possui uma dimensão qualitativa que separa a ambos os conceitos mas, ainda assim, a Igreja Católica mantém em sua representação a personalidade humana falha que, embora transcenda a de todos os indivíduos, não se resolve na perfeição do divino.

Esta forma de representação que para Schmitt é politicamente genuína, não se confunde com a experiência liberal do conceito. Os conceitos de representação e de identidade em Schmitt são distinguíveis apenas no plano abstrato, mas não em sua concretude histórica (cf. CÓRDOVA VIANELLO, 2010, p. 253) no qual são indissociáveis (cf. CÓRDOVA VIANELLO, 2010, p. 255), e pressupõem a unidade política de um povo, ou seja, a demanda da existência de uma coletividade homogênea capaz de atuar como um sujeito unitário (cf. CÓRDOVA VIANELLO, 2010, p. 252). Há dois níveis de identidade, e o primeiro deles diz respeito aos valores, ideais e instituições estimadas por uma comunidade em torno das quais emerge a possibilidade da representação unívoca por um só líder capaz de encarnar este conjunto, perspectiva desde a qual Campderrich Bravo conclui que a representação em 
Schmitt está conectada a um caráter homogêneo (cf. CAMPDERRICH BRAVO, 2011, p. XXIV), perspectiva que pode ser questionada pela exposição laudatória de Schmitt da Igreja Católica como complexio oppositorum e síntese aglutinadora de opositores. O segundo dos níveis de identidade diz respeito à experiência existencial de uma só figura capaz de encarnar o povo mediante sua identificação com ele.

Este movimento de Schmitt pressupõe uma necessidade subjacente, justamente o primeiro dos níveis de identidade citado logo acima, e que redundaria na homogeneidade do povo. Esta homogeneidade é que permitiria a aclamação do líder, leitura que aponta para a necessária forja da identidade entre governante e governados, representante e representados, o que na gramática de Schmitt, é a referência a aqueles que estão em posição de mando e os demais que se encontram em posição de prestar obediência ou, ainda, se preferirmos, entre o dominante (Herrscher) e os dominados (Beherrschten). Segundo uma versão liberal-contraturalista, tal relação de representação se daria entre os súditos outorgantes do poder a um soberano, figura que deve exercer o poder tão somente nos limites da outorga (cf. HOBBES, 1992, p. 188), e exercendo-o apenas nestes limites é que honra a função de representação. Neste sentido, em uma democracia subjaz a noção de que é necessária uma identidade entre governantes e governados (cf. POLACK, 2011, p. 56), pois se não for assim o governo seria pura tirania (cf. SÁ, 2015, p. 140).

Para Schmitt é indiscutível que a instituição que reúne as melhores características da representação é a Igreja Católica, em muito maior grau, inclusive, que o Estado moderno (cf. CAMPDERRICH BRAVO, 2011, p. XXV), que para Schmitt apresentava-se em franca decadência em face do processo de secularização em curso, cujo paralelo acompanhamento da racionalização ${ }^{10}$ - e suas aspirações a um governo

10 Há uma clara tensão entre secularização e racionalização em Schmitt claramente resolvida em favor da primeira. A este respeito comenta Galli que para Schmitt a secularização é" [...] no es sólo"vaciamiento" de la religión [...] sino que traduce en formas políticas instancias de libertad que se daban de otra forma" (GALLI, 2011, p. 84). Por outro lado, é preciso considerar que 0 impacto da razão sobre as estruturas teológicas do Estado pode ser percebido pela crise aberta na modernidade, que Galli observa através do embate dos indivíduos com as condições encetadas por esta razão moderna, pois esta se esforçaria em fundamentar a ordem sob a qual os indivíduos, procedendo a tentativa de fazer dela "[...] una máquina supuestamente

Rev. Filos., Aurora, Curitiba, v. 29, n. 47, p. 455-479, maio/ago. 2017 
tecnicista - e do avanço da economia deteriorava as instâncias de poder e da tipologia de autoridade contempladas na teoria schmittiana incrustada no Catolicismo Romano. Este era de todo avesso ao racionalismo economicista, pautado pela satisfação das necessidades criadas no homem pelo próprio sistema, e é assim que se constrói uma nova realidade, pois "Na grande metrópole moderna foi criado uma espécie de edifício no qual tudo é calculável" (SCHMITT, 2008, p. 23).

É o conteúdo que habita o interior do catolicismo que não pode menos do que repelir em absoluto este tipo de sistema racionalista, objetivo que passa a habitar o econômico no mundo moderno, ou seja, "Este sistema de objetividade imperturbável pode horrorizar um católico piedoso, e isto, precisamente, por sua racionalidade" (SCHMITT, 2008, p. 23), alerta importante para o cenário que se desenhava. O que está sendo ao fundo rechaçada é uma visão burguesa em prol da neutralidade política que afasta a religião de seu núcleo político, ao tempo em que alerta que catolicismo traz em seu âmago a potencialidade específica para ser aplicada à esfera do político (cf. SÁ, 1998, p. 7). Através do diálogo entre ambos é possível deslindar os meandros da crise da legitimação moderna (ver BLUMENBERG, 2008), que aponta para a busca de razão e força no contratualismo de viés liberal. Este traz consigo a força do economicismo tecnocrático, e sua capacidade de representação do mundo tem potencial para causar horror ao homem católico, eis que a racionalidade com a qual opera considera apenas a satisfação de necessidade, mas não os fins, ou seja, que

O genuíno medo católico procede de saber que o conceito do racional tergiversa de uma forma fantástica para o sentimento católico, pois se chama "racional" a um mecanismo de produção que está a serviço da satisfação de quaisquer necessidades materiais, sem que se pergunte

a disposición del indivíduo, [...] en realidad es una máquina que lo domina" (GALLI, 2011, p. 85). Este movimento alcança Schmitt através de sua recepção de Ensayos sobre el catolicismo, el liberalismo y el socialismo (1851), que D’Auria reputa ser uma condenação da modernidade em seu conjunto, vale dizer, da Reforma e do liberalismo, mas também do socialismo e do laicismo (cf. D’AURIA, 2010, p. 63), conjunto de valores que constitui um alargamento dos horizontes pré-modernos ou medievais tardios. 
pela única racionalidade essencial, qual seja, a dos fins, para os quais se dispõem o supremo mecanismo racional. (SCHMITT, 2008, p. 26) ${ }^{11}$.

Este processo descostura a racionalidade dos fins e permanece centrado na racionalidade dos meios, descose e tritura, portanto, a importância do político. Em combate, Schmitt recorre a identificação entre governante e governados, não obstante a melhor perspectiva desde uma perspectiva realista e democrática da política indicasse sob tal estratégia a alta probabilidade de que deparássemos com a pura dominação. Esta não é uma leitura da representação compatível com aquela realizada por sólidas versões do parlamentarismo democrata-liberal, ${ }^{12}$

11 Neste aspecto, a crítica schmittiana é direta ao indicar que o mundo econômico pode estar em perfeito acordo com tudo, mas desde que os seus meios técnicos alcancem os objetivos afinados com os seus interesses, ou seja, "Das ökonomische Denken vermag diese katholische Angst gar nicht zu perzipieren; es ist mit Allem einverstanden, wenn es sich mit den Mitteln seiner Technik beliefern läßt" (SCHMITT, 2008, p. 26). Schmitt foca a sua crítica na racionalidade técnica utilizada pelo mercado em tão somente satisfazer às demandas, à construção de uma engenharia de produção capaz de suprir e satisfazer quaisquer necessidades materiais que sejam apresentadas. A crítica schmittiana se centra em que a racionalidade técnica se desentende da análise do que ele reputa ser a "única racionalidade essencial", qual seja, a dos fins. Em verdade, a aplicação política desta crítica schmittiana está orientada pelos mesmos princípios que pretende criticar, posto que o mercado, tanto quanto 0 autoritarismo, o fascismo e o totalitarismo, tão somente consideram os fins ao arrepio de qualquer ponderação sobre 0 valor dos meios utilizados. Na crítica schmittiana pairam os valores do catolicismo como fins a ser considerados em sua essência axiológica, algo que, verdadeiramente, a racionalidade mecanicista da economia passa ao largo. Se da doutrina católica podemos dizer que não permanece alheia aos meios para alcançar os seus fins, que são supremos, desde logo, a racionalidade mecanicista da economia tem similar preocupação com os seus fins, mas desde um ângulo diverso, priorizando os fins a despeito de quaisquer meios necessários para alcançá-los. Schmitt foca em sua crítica a racionalidade do mercado. Não obstante a sua crítica, Schmitt não parece ter sido fiel a ela em sua íntegra, pois a instrumentalização da racionalidade alheia a consideração dos altos fins é movimento que foi explicitado ao menos durante 0 seu período de adesão ao nacional-socialismo, no qual, sabidamente, a razão operativa do regime que Schmitt apoiou obedeceu de forma rasa a esta lógica dos fins em desconsideração a quaisquer meios ou valores, ou seja, algo que $S$ chmitt criticou que 0 mercado não obedecia, a única racionalidade essencial, a dos fins. Uma tradução livre para o trecho citado acima nesta nota é: "0 pensamento econômico não pode perceber este medo católico em absoluto pois está conforme com tudo, desde que possa obtê-los pelos seus meios técnicos".

12 É certo que o parlamentarismo democrático-liberal sempre foi um dos importantes alvos da crítica schmittiana reputado como falsa democracia, sendo bem conhecido o fato de que Schmitt esteve longe de manter qualquer simpatia pela democracia em seu sentido liberal-parlamentar. Benjamin também reforça esta perspectiva ao sustentar que "Não há, de forma alguma, qualquer defesa da democracia em Schmitt. É exatamente do oposto que se trata. Schmitt é um dos mais argutos críticos da tradição democrática. E 0 que torna tal crítica tão interessante é que ela é feita ao coração mesmo da idéia de democracia" (BENJAMIN, 2008, p. 418). Sem embargo, comentaristas como Ruiz Miguel todavia logram encontrar traços da verdadeira democracia em Schmitt, para o que, supostamente, bastaria não tirássemos as palavras do autor de seu contexto (cf. RUIZ MIGUEL, 2000, p. XXVI).

Rev. Filos., Aurora, Curitiba, v. 29, n. 47, p. 455-479, maio/ago. 2017 
as quais Schmitt tão veementemente criticou $^{13}$, e que mantiveram contato com a anunciada oposição crítica da Igreja Católica relativamente ao liberalismo. Esta posição foi pública e influentemente anunciada em 1864 através da Encíclica Syllabus, ${ }^{14}$ de forma impactante muito presente na obra política de Donoso Cortés (ver DONOSO CORTÉS, 2007), não apenas lida como altamente influente em Schmitt (cf. D'AURIA, 2010, p. 62), orientando um movimento de clara recepção política laica das formas políticas teológicas.

\section{Representação, Poder e Democracia}

Do ponto de vista temporal o problema básico da representação começa a ser posto no momento inaugural da vida política. É preciso considerar o instante fundacional social e logo observar que, quiçá, quando estamos frente a minúsculas esferas de poder, eis que a representação política em sua modelação contemporânea pode ser dispensável. Entendida a representação como o ato de substituir alguém no ato deliberativo, a manifestação direta de vontade deixa de ser factível quando as sociedades ultrapassam dimensões mínimas e se tornam complexas, quando então é inviável que a representação ocorra pessoalmente - ideal plenamente realizado da identidade, concretizada entre o governante e os governados -, por cada um dos interessados

13 A crítica da representação no pensamento autoritário de Schmitt é realizada, como bem observa Sá, em um marco mais amplo que envolve as análises que tem como objeto o Estado de direito, à legitimidade política e a democracia (cf. SÁ, 2015, p. 130).

14 É indubitável que a Igreja Católica apresenta uma estrutura hierárquica bastante rígida e que opera sob um controle piramidal rígido cuja resolução final se encontra na figura do Papa. Neste sentido, Pinto chama a atenção para o papel isolado do laicado, em posição de absoluto alheamento às decisões tomadas nesta estrutura, posto que "[...] constituyen la base de la pirámide, siendo los receptores de la gracia divina que le transmite sacralmente la jerarquía eclesiástica" (PINTO, 2003, p. 94). De forma similar à recepção de tal estrutura por Schmitt, uma vez aplicada ao Estado permite observar 0 processo relacional do povo com o seu soberano. Neste sentido a referência de Kalyvas sobre a Encíclica papal de Pio X de 1906, que seria pertinente para esclarecer quão útil é a estrutura hierárquica da Igreja Católica para sustentar um regime autoritário em sua transmutação política, e assim sustenta que "La Iglesia es por naturaleza una sociedad desigual, está constituída por dos categorías de personas: los pastores y la grey. Sólo la jerarquía promueve y controla...el deber de la masa es el de aceptar ser governada y seguir con sumisión las órdenes de aquellos que la guían" (apud PINT0, 2003, p. 94). 
na deliberação em uma pluralidade superlativa de matérias. Em sociedades complexas a representação direta é impossível, posto que espaço onde o número de indivíduos virtualmente obsta a qualquer ideal deste gênero nos assuntos públicos.

Quando em meados do século XVIII a fundamentação absolutista do poder ruía em favor da emersão das forças populares através da Revolução Francesa, então ocorria movimento de separação entre Estado e Igreja, com isto teve vez e espaço a reorientação do problema da representação para outra dimensão, eis que, até então - tema que Hobbes retoma de Bellarmino - estava em discussão a distinção entre poder temporal e poder espiritual, que Hobbes desqualificara como mera "palabrería" (HOBBES, 1992, p. 444), pois, de fato, o primeiro estaria submetido ao segundo (cf. Ib.). Foi contra esta submissão explícita do poder temporal ao poder espiritual e, em especial, ao da Igreja Católica que operaram os movimentos de corte ilustrado do século XVIII, pois a sua pluralidade e titularidade de poder localizadas à base, no povo - e aqui o eixo que o posiciona como titular do poder constituinte - , era incompatível com uma perspectiva teológica do poder em que sobressaía a unidade encarnada na figura de um só, o monarca ou soberano, ou seja, que "[...] sólo en la articulación con una instancia concreta de mando, con el soberano, es posible el surgimiento de la unidad política"(PÁEZ CANOSA, 2016, p. 614).

Este deslocamento da origem legitimadora do poder ocorreu sob a projeção de que o direito divino dos reis não mais poderia impor as normas jurídicas e tampouco exigir obediência, mas sim a base popular, na qual passaria a residir a soberania. Para Schmitt tal movimento é marcado por um racionalismo operante contra o catolicismo (cf. SCHMITT, 2008, p. 5), cujo âmbito teológico era dotado de um racionalismo diverso e de estrato superior. Nestes termos, o catolicismo é sempre promotor de uma "[...] fe ciega en la posibilidad de sustituir la política, la autoridad, la religión, el Estado y, en general, todo ideal normativo por una pura administración automática científico-técnica de las cosas y de las personas [...]" (CAMPDERRICH BRAVO, 2011, p. XLIII). A tentativa de subsumir o poder espiritual ao poder civil é atentatória às formas do catolicismo e a Schmitt, operativa de uma racionalidade que Sá qualificou 
como representativa (cf. SÁ, 1998, p. 12), no mesmo sentido da leitura de Páez Canosa, que já abrindo nova vereda, indica que a representação se contrapõe e resiste a todas as tentativas de ser concebida como mero procedimento técnico (cf. PÁEZ CANOSA, 2016, p. 613).

A concepção hierárquica do poder e da representação em Schmitt se inclina pelo modelo retirado da Igreja Católica e que já havia sido desenhado por Donoso Cortés como aquele que vem de cima (ditadura do sabre), e não pelo poder emergente desde baixo (ditadura do punhal), elaboração que denota a estratégia aristocrática. Desde perspectiva entrecortada com a filosofia política hobbesiano-schmittiana, Dotti afirma que o soberano enquanto ator-representante torna possível a existência do povo em seu sentido político-jurídico (cf. DOTTI, 2014, p. 38), sendo que a condição de possibilidade do soberano é que deriva da existência do agrupamento humano. Polack esclarece algo mais ao sustentar que a representação em Schmitt é que produz a unidade, mas que "El Pueblo es entendido como la voluntad sin forma, y es el Ser político el que crea todas las formas concretas de organización del pueblo" (POLACK, 2011, p. 58).

A articulação destes movimentos deixa entrever uma única raiz de viés autoritário e teológico, em oposição aos primeiros passos da democracia e sua inspiração iluminista. Inversa via, Donoso Cortés desenvolveu concepção de genuína liberdade de corte teológico apenas realizável no catolicismo romano (cf. D'AURIA, 2010, p. 63), mas que logo se revelaria corrosiva desta concepção. De corte dogmático e excludente da pluralidade (redutora e homogeneizante), esta concepção tortuosa da liberdade todavia habita a contemporaneidade e de forma latente habita as profundezas ocultas do conceito de democracia para o qual os esforços conservadores migraram e competentemente a mobilizam para fins autoritários.

Este caminho não seria o indicado para a consolidação da democracia, que apenas poderia ser realizada no plano da imanência, e não no da transcendência, posto que é do povo que o governo emana (cf. BENJAMIN, 2008, p. 424). O que estava em oposição era a legitimidade que para alguns era vinda de cima, de uma esfera divina, apenas aceitável para quem tem fé, e para outros, de uma ordem de legitimidade 
diversa, vinda de baixo, potencialmente compartilhável por todos indivíduos pertencentes a uma determinada sociedade. Em sentido idêntico é a crítica de Campderrich Bravo ao sustentar que a Igreja Católica representava o modelo ideal de autoridade política, ${ }^{15}$ alternativa capaz de "[...] ofrecer al desfalleciente y muy cuestionado poder del Estado moderno" (CAMPDERRICH BRAVO, 2011, p. XXIII), mas que, de qualquer sorte, era representativo de um modelo autoritário, aproveitando o Mystici Corporis eclesial para a figura de um soberano temporal que, assim, orientaria a sua legitimidade desde cima, e não desde baixo (cf. Ib.), não da base hierárquica do poder, vale dizer, do povo.

A emersão do poder popular exigiu a constituição de uma nova forma de poder, cuja origem popular precisaria de formas políticas que agregassem o seu querer ao conteúdo das normas jurídicas e lhes desse sentido. Este é precisamente um dos graves problemas das democracias, qual seja, o da brecha que pode ser observada, mais ou menos intensa e grave entre o querer dos governados e as decisões a este respeito tomadas pelos governantes. A consolidação nestes últimos de uma força autônoma confirma uma forma específica de poder avessa ao conceito de democracia popular.

A transformação do querer político da população em normas jurídicas vinculatórias pela via representativa ocorre sob a pressão da inviabilidade física de reunir em um mesmo espaço ao conjunto dos cidadãos para o processo deliberativo, algo inviável na medida em que as sociedades se tornaram mais complexas. Neste sentido é preciso convergir com a ideia de que, por si só, o conceito de democracia direta seria inviável a qualquer espécie de sociedade, posto que, como recorda Magalhães, isto “[...] equivaleria a ignorar-se a presença fática

15 É importante considerar que no bojo da Igreja Católica a hierarquia e a estrita obediência funcionam sob a liga da fé incondicional na divindade, algo que no mundo temporal não é possível, exceto sob intensa manipulação, típica dos regimes autoritários. 0 católico se porta ante a Igreja como um ser à procura do infinito e da virtude absoluta enquanto que na esfera temporal remanesce tão somente a finitude, a precariedade e o conflito como vetores da existência, ou seja, segundo a gramática teo-antropológica de Schmitt, que "A ligação das oposições estende-se até às últimas raízes sociais e psicológicas dos motivos e representações humanas" (SCHMITT, 1998, p. 23). Portanto, a mediação teológica difere essencialmente das possibilidades da mediação secular. Nestes termos convergimos com Galli ao destacar que o catolicismo para Schmitt foi "[...] sólo una "vía", sólo un "medio" cultural e ideal para sustraerse a la autovalorización de lo moderno, a la ideologia protestante de la"secularización productiva"; no, por cierto, un "fin" religioso o político" (GALLI, 2011, p. 87). 
e anterior do próprio povo [...]" (MAGALHÃES, 2011, p. 36), isto é, e taxativamente, que "[...] uma identidade absoluta do povo consigo próprio enquanto unidade política é também irrealizável [...] [pois] nem uma democracia directa, que possa reunir, num mesmo lugar, todos os cidadãos, se livra da noção de representação" (MAGALHÃES, 2011, p. 36). Sem embargo, o conceito de representação em Schmitt opera de forma diversa, permitindo a identidade do povo consigo mesmo através da figura do soberano.

No conceito de representação schmittiano está em causa a articulação entre unidade e a homogeneidade por uma singular via cognitiva da democracia, pressupondo uma comunidade de iguais (cf. POLACK, 2011, p. 56). Opera na categoria de representação schmittiana a ideia paulina de que "Nós, muitos, somos um só corpo de Cristo" (Rm 12, 5), multiplicidade de indivíduos que, sem embargo, não coexiste em suas diferentes singularidades no corpo de Cristo, senão enquanto perfeita comunhão. A transmigração do teológico articulado sob a fé para o campo do político em que o plural se resume na figura do soberano redundará na armadilha autoritária que o conceito de democracia schmittiano comporta. A partir desta perspectiva acerta a interpretação de Magalhães ao indicar que a "[...] unidade política do povo não se esgotaria na assembleia popular - ela existiria, temporal como espacialmente, para além dela" (MAGALHÃES, 2011, p. 36).

Admitida a inevitabilidade da representação resta em destaque o problema de como ele se coloca no bojo de uma sociedade em que a via de legitimação do poder esteja vinculada ao povo, e em cujo nome o poder deve ser exercido, embora para Schmitt a representação não esteja ligada ao conceito de democracia (cf. POLACK, 2011, p. 57). Nesta esfera de criação da norma jurídica e de toda uma estrutura de poder sob a qual viver, importa retomar a ideia intuitiva de que o mundo natural não oferece referenciais axiológicos ou morais sobre os quais o homem deva construir o mundo do direito, senão que é pura criação humana e não revelação sobre a qual algum ente detenha o controle e completo poder de discernir o bem e o mal.

A este respeito convém recordar a leitura de Espinosa realizada por Benjamin que o leva a concluir que na imanência "[...] não 
há nenhuma lei ou regra que tenha mais legitimidade que outra" (BENJAMIN, 2008, p. 422), e que se as coisas são mesmo assim, então, podemos concluir que em tal nível radical de indeterminação "[...] não há "naturalmente" nenhuma hierarquia dada sobre quem pode fazer a lei ou regra, a única solução que resta é, então, a deliberação" (BENJAMIN, 2008, p. 422), restando daí a necessidade de deliberação e da representação como condição para a realização da tarefa política. Assim, admitindo que há igualdade no ponto de partida entre os sujeitos deliberantes é possível supor que a realização do princípio democrático em sua origem seria que a escolha das normas fundamentais da vida em sociedade se desse através da intervenção do amplo coletivo e de forma direta. Esta não pode ser a opção prática das democracias, razão pela qual subsistem legítimos questionamentos sobre a real qualidade democrática das instituições que reputamos ser democráticas.

\section{Considerações finais}

Desde esta perspectiva a via constitutiva da sociedade, mas também as suas vias permanentemente reconstitutivas, demandam a configuração e a reconfiguração das esferas de poder, expressando com isto a vitalidade e a dinamicidade da vida em uma sociedade com pretensões de afirmar a democracia. Mas se a democracia em sua matriz pode ser compreendida como a deliberação popular realizada de forma mediata por cada um de seus interessados, expressando variante indireta que a democracia propõe, então, a introdução da representação supõe alguns problemas a resolver. Um óbice proposto pela representação é que ela quebra de uma suposta e almejada unidade original, que a circunstância em que alguém diretamente intervém no sentido de deliberar os assuntos que lhe dizem respeito, com direito a voz e voto.

Identificada a unidade para a dualidade real, importa salientar que o modelo seria superior ao instrumental filosófico oferecido pelo hegelianismo na medida em que descarta a síntese capaz de superar os opostos, senão que inclui a ambos os termos em conflito e os resolve em uma suposta harmônica unidade, livre de tensões e oposições 
(ver MARDER, 2008, p. 29). Esta é uma síntese que a Igreja Católica havia realizado em seu interior através da figura do Papa, incapaz de errar publicamente e, por isto, adequada representante terrena da divindade, exalando a legitimidade para obter a voluntária submissão e obediência tão necessária às autoridades temporais civis e que, não por outra razão, se coloca como pergunta fundadora da política na modernidade e sua necessidade de obtenção de legitimidade e de autoridade (cf. PÁEZ CANOSA, 2016, p. 616).

O Papa encarna em si a multiplicidade e a complexidade da Igreja Católica, sociedade marcada pela diversidade de visões de mundo, cujo único ponto de convergência é a fé depositada em Deus. Esta perspectiva encontra o seu equivalente em Schmitt na substituição do debate e da discussão parlamentar pela mera aclamação, concretizando movimento redutor do uso da razão pública ao mero elogio da massa realizado ao líder a quem todos prestam pública devoção e estrita obediência. Schmitt encontra na figura unitária capaz de exercer a representação o modelo ideal de autoridade que é eminentemente pessoal (cf. CAMPDERRICH BRAVO, 2011, p. XXVI).

Sob tal perspectiva a autoridade papal realiza intervenção última e infalível (cf. SCHMITT, 2008, p. 14), e Schmitt reaviva o conceito do Concílio Vaticano I de final do século XIX (1869-1870), compreensivo de autoridade fortemente hierárquica que foca na figura papal a última fonte de poder cujas decisões são inquestionáveis e irreversíveis (cf. CAMPDERRICH BRAVO, 2011, p. XXIX). No mundo temporal é através de autoridades similares capazes de reunir o complexo de opostos que se encontra modelo operativo para a pacificação política. A seu modo, Schmitt detectou modelo político de viés laicizante na obra de Hobbes ao indicar que "Una multitud de hombres deviene una persona cuando estos hombres son representados por un hombre o una persona [...]" (HOBBES, 1992, p. 137) e à raiz disto conclui ele que "[...] es la unidad del representante, y no la unidad de los representados, lo que hace a la persona una [...]" (HOBBES, 1992, p. 137).

A Igreja Católica opera ao mesmo tempo como eixo e ápice da centralização, concretizando no Papa o vértice da representação de todas as oposições presentes no seio da Igreja, e isto leva Schmitt a 
reconhecer a virtude fortemente centralizadora do modelo do catolicismo (cf. SCHMITT, 2008, p. 11), por certo, inspirado no Império Romano (cf. SCHMITT, 2008, p. 10), modelo em que a decisão era tomada por agente perfeitamente identificável. Schmitt atribuiu à Igreja Católica a virtude de abarcar todas as contradições através de diversos meios, que "Parece não haver oposição que ela não abarque. Desde há muito que ela se glorifica por unir em si todas as formas de Estado e de governo" (SCHMITT, 1998, p. 20-21). Este resumo da complexidade de opostos encarna para alguns comentaristas o modelo perfeito da representação sob a forma da unidade que não dissolve a pluralidade, eficiência da Igreja Católica que se evidenciaria em sua permanência histórica (ver SCHMITT, 1996). Sem embargo, esta fórmula não atenta suficientemente para o fato da imposição obsequiosa do silêncio do dissidente ou, na pior das hipóteses, de seu esmagamento ou, ainda, na transposição da matéria ao campo político, que é uma decisão estatal e não o diálogo que podem oferecer adequada resposta às situações de desordem (cf. PINTO, 2003, p. 97).

Sob este modelo clássico de representação da Igreja Católica não remanesce espaço para a dissidência ativa, senão para o silêncio temeroso, o que projeta a sua atualidade. Schmitt chama a atenção para que o catolicismo contém a virtude de aglutinar internamente os povos, que teria sido capaz de emprestar força de resistência a não poucas nações (cf. SCHMITT, 2008, p. 10), cuja força é perceptível através de sua persistência no tempo (cf. SCHMITT, 2008, p. 2).

Parece subsistir ligeiro equívoco do argumento de que a infalibilidade da decisão papal possa dirimir conflitos (cf. SÁ, 2015, p. 133), pois o que realmente ocorre é uma contenção das oposições, um refreamento de oposições que não oferecem resistência à luz da intervenção papal. O elogio a esta noção é calçado em debilidade consistente em que não dirime ou resolve o conflito, mas apenas o reprime, e ao continuar latente e pulsante na complexidade do corpo sobre o qual intervém, em verdade, está a ampliar a sua potencialidade destrutiva.

A figura política que faz regredir os ânimos conflitivos não resolve este núcleo indissociável da diversidade, não pode eliminar os conflitos mantidos no âmago da vida social em que os indivíduos 
interagem senão que, ao tergiversar, tão somente os sufoca e, em sua intimidade, agride. A representação desde uma perspectiva democrático-libertária mais do que de síntese, precisa de mediação, mais do que concludente ou taxativa, precisa ser itinerante, mais do que retórico-dogmática, precisa ser persuasivo-dialógica.

\section{Referências}

BARBERI, M. S. Il senso del politico. Saggio su Carl Schmitt. Milão: Giuffré, 1990.

BARNETT, C. Deconstructing radical democracy: articulation, representation, and being-with-others. Political Geography. v. 23, n. 5, p. 503-528, 2004.

BENJAMIN, C. C. Schmitt e o problema da democracia. Nostalgia da transcendência ou a representação como questão para a democracia. Kriterion, n. 118, p. 417-441, 2008. Disponível em: <http://www.scielo.br/pdf/kr/v49n118/08.pdf> Acesso em: 20 mar. 2013.

BLUMENBERG, H. La legitimación de la Edad Moderna. Valencia: Pre-textos, 2008.

CAMPDERRICH BRAVO, R. Estudio Preliminar. In: SCHMITT, C. Catolicismo Romano y forma política. Madrid: Tecnos, 2011. p. IX-LXXXVIII.

CASTIGLIONE, D.; WARREN, M. E. Rethinking Democratic Representation: Eight Theoretical Issues. Prepared for delivery to "Rethinking Democratic Representation". Centre for the Study of Democratic Institutions, University of British Columbia, May 18-19, 2006. Disponível em: <http://www.politics.ubc. ca/fileadmin/user_upload/poli_sci/Faculty/warren/Rethinking_Democratic_ Representation_May_2006.pdf>. Acesso em: 7 mai. 2008.

CÓRDOVA VIANELLO, L. Derecho y poder. Kelsen y Schmitt frente a frente. México: Fondo de Cultura Económica; UNAM, IIJ, 2009.

D'AURIA, A. Teologia, Política y Anarquismo. Revista Crítica Jurídica. n. 9, p. 59-82, Enero/Junio, 2010. 
DONOSO CORTÉS, J. Ensayo sobre el catolicismo, el liberalismo y el socialismo. Madrid: Editorial Biblioteca Nueva, 2007.

DOTTI, J. E. La representación teológico-política en Carl Schmitt. Avatares filosóficos, Universidad de Buenos Aires (UBA), n. 1, 2014.

GALLI, C. La mirada de Jano. Ensayos sobre Carl Schmitt. México: Fondo de Cultura Económica, 2011.

HOBBES, T. Leviatán. Madrid: Alianza Universidad, 1992.

KELLY, D. Carl Schmitt's Political Theory of Representation. Journal of the History of Ideas. v. 65, n. 1, p. 113-134, Jan., 2004. Disponível em: <http://www.consiglio.regione.campania.it/cms/CM_PORTALE_CRC/servlet/ Docs?dir=docs_ biblio\&file=BiblioContenuto_862.pdf $>$. Acesso em: 10 mar. 2015.

MAGALHÃES, P. M. T. de. A teoria da representação na Alemanha de Weimar: Schmitt, Kelsen e Leibholz. Dissertação de Mestrado em Ciência Política e Relações Internacionais, variante de Ciência Política, realizada sob a orientação científica de Pedro Tavares de Almeida. Julho de 2011. Disponível em: $<$ https://run.unl.pt/bitstream/10362/7092/1/A\%20teoria\%20da\%20 representa\%C3\%A7\%C3\%A3o\%20na\%20Alemanha\%20de\%20Weimar.\%20 Schmitt,\%20Kelsen\%20e\%20Leibholz.pdf>. Acesso em: 13 mai. 2015.

MARDER, M. Carl Schmitt's “Cosmopolitan Restaurant": Culture, Multiculturalism, and Complexio Oppositorum. Telos. v. 142, p. 29-47, Spring, 2008. Disponível em: <http://www18.georgetown.edu/data/people/mm892/publication-35557.pdf> Acesso em: 12 out. 2013.

McCORMICK, J. Carl Schmitt's Critique of Liberalism. Against Politics and Technology. Cambridge: Cambridge University Press, 1997.

PÁEZ CANOSA, R. Aspectos de una subjetividad política estatal: representación y obediencia. In: BUENO, R. (Org.). Carl Schmitt hoje: política, direito e teologia. São Paulo: Max Limonad, 2016. p. 603-622.

PINTO, J. Carl Schmitt y la reivindicación de la política. Buenos Aires: Proyecto Editorial, 2003. 
POLACK, A. Democracia, representación y ciudadanía en el pensamiento de Carl Schmitt. Reflexión Política. v. 13, n. 26, p. 54-64, dici., 2011.

RUIZ MIGUEL, C. Estudio Preliminar. In: SCHMITT, C. Catolicismo Romano y Forma Política. Madrid: Tecnos, 2000. p. IX-XLII.

SÁ, A. F. Democracia representativa: as críticas de Carl Schmitt. INTERthesis: Revista Internacional Interdisciplinar, v .12, n. 1, p. 130-146, 2015. Disponível em: <http://dx.doi.org/10.5007/1807-1384.2015v12n1p130>. Acesso em: 23 fev. 2016.

SÁ, A. F. Prefácio. In: SCHMITT, C. Catolicismo Romano e forma Política. Lisboa: Hugin, 1998. p. 7-16.

SCHMITT, C. Catolicismo Romano e forma Política. Lisboa: Hugin, 1998.

SCHMITT, C. Römischer Katholizismus und politische Form. Stuttgart: KleinCotta, 2008.

SCHMITT, C. Teologia Política. Madrid: Trotta, 2009.

SCHMITT, C. Berlín, 1907. Res Publica. Revista de Historia de las Ideas Políticas. v. 19, n. 1, p. 309-342, 2016.

SCHMITT, C. La visibilidad de la Iglesia: una reflexión escolástica. In: Daimon: Revista de Filosofía. Carl Schmitt. Entre teología y mitología política. n. 13, p. 11-20, 1996.

TRUCCO, O. Schmitt: identidad y representación como princípios políticos. Identidades. Núm. 2, año 2, p. 24-29, Junio, 2012. Disponível em: <https://iidentidadess.files.wordpress.com/2012/06/02-identidades-2-2-2012-trucco2.pdf $>$. Acesso em: 12 out. 2016.

Recebido: 10/05/2017

Received: 05/10/2017

Aprovado: $12 / 06 / 2017$

Approved: 12/06/2017 